\title{
A bioética da intervenção como possibilidade de inclusão social de pacientes com doença falciforme em tempos de COVID-19*
}

\author{
Clara Gustin ${ }^{\mathrm{a}}$ - Willian Pimentel ${ }^{\mathrm{b}}$ - Marcelo Sarsurc $\boldsymbol{\text { - Luciana Dadalto }}{ }^{\mathrm{d}}$
}

Resumo: este artigo discute a exclusão social vivida pelos indivíduos brasileiros com a doença falciforme, sob a perspectiva da bioética de intervenção. Trata-se de uma enfermidade na qual o afetado herda de seus progenitores o gene responsável pelo formato diferenciado da hemoglobina; ademais, apresenta maior incidência na população negra, uma vez que a alteração do formato da hemoglobina foi resultado da evolução do próprio corpo para evitar a contração da malária no continente africano. Além da exclusão social que a população negra sofre, há, ainda, um maior grau de preconceito advindo dos efeitos da doença. Revela-se que as dificuldades enfrentadas pelos

* Artigo de revisão.

a Graduanda de Direito da Pontifícia Universidade Católica de Minas Gerais, Brasil. Membro do Grupo de Estudos e Pesquisa em Bioética do Centro Universitário Newton Paiva, Belo Horizonte, Brasil. Correio eletrônico: claradesousagustin@gmail.com ORCID: https://orcid.org/0000-0001-6529-4706

b Pós-graduando em Direito Digital pelo Instituto de Sociedade e Tecnologia, Universidade Estadual do Rio de Janeiro, Brasil. Advogado. Graduado em Educação Física. Membro pesquisador do Grupo de Estudos e Pesquisa em Bioética do Centro Universitário Newton Paiva, Belo Horizonte, Brasil.

Correio eletrônico: willianpimentel.ef@gmail.com

ORCID: https://orcid.org/0000-0002-3910-7353

c Doutor e mestre em Direito pela Universidade Federal de Minas Gerais, Brasil. Atua como professor nos cursos de pós-graduação (lato sensu) em Direito Ambiental e em Direito Minerário do Centro de Estudos em Direito e Negócios. Integrante da Comissão de Advocacia Criminal da Ordem dos Advogados do Brasil, Minas Gerais. Atua como advogado criminalista. Coordenador do Grupo de Estudos e Pesquisa em Bioética, Belo Horizonte, Brasil.

Correio eletrônico: msarsur@gmail.com ORCID: https://orcid.org/0000-0002-9580-0275

d Doutora em Ciências da Saúde pela Faculdade de Medicina da Universidade Federal de Minas Gerais, Brasil. Mestre em Direito Privado pela Pontifícia Universidade Católica de Minas Gerais, Brasil. Professora da Escola de Direito do Centro Universitário Newton Paiva, Belo Horizonte, Brasil. Coordenadora do Grupo de Estudos e Pesquisa em Bioética do Centro Universitário Newton Paiva. Correio eletrônico: lucianadadalto@gmail.com ORCID: https://orcid.org/0000-0001-5449-6855 
acometidos são agravadas em decorrência da COVID-19. Portanto, a criação de políticas públicas que se alicercem nos parâmetros da bioética da intervenção, cujo foco principal é a vulnerabilidade e os desafios persistentes da sociedade, é proposta como possível ação para minorar as consequências da doença falciforme na população por ela afetada.

Palavras-chave: doença falciforme; exclusão social; bioética da intervenção; COVID-19

Recibido: 01/04/2020

Aceptado: 07/10/2020

Disponible en línea: 23/04/2021.

Cómo citar: Gustin C, Pimentel W, Sarsur M, Dadalto L. A bioética da intervenção como possibilidade de inclusão social de pacientes com doença falciforme em tempos de COVID-19. Rev. latinoam. bioet [Internet]. 23 de abril de 2021 [citado $8^{\circ}$ de abril de 2021];20(2): 42-53. Disponível em: https://doi. org/10.18359/rlbi.4703

\title{
La bioética de la intervención como posibilidad de inclusión social de pacientes con enfermedad de células falciformes en tiempos de COVID-19
}

Resumen: el artículo discute la exclusión social vivida por individuos brasileños con la enfermedad de células falciformes, desde la perspectiva de la bioética de intervención. Se trata de uma enfermedad en que el afectado hereda de sus progenitores el gen responsable del formato diferenciado da hemoglobina; asimismo, presenta más incidencia en población negra, una vez que la alteración del formato da hemoglobina resultó de la evolución del propio cuerpo para evitar la malaria en el continente africano. Además de la exclusión social que la población negra sufre, hay aun un mayor grado de discriminación que proviene de los efectos de la enfermedad. Se revela que las dificultades afrontadas por los enfermos se ven agravadas debido a la COVID-19. Por lo tanto, la creación de políticas públicas que se fundamenten en los parámetros de la bioética de la intervención, cuyo enfoque principal es la vulnerabilidad y los retos persistentes de la sociedad, se propone como posible acción de reducir las consecuencias de la enfermedad falciforme en la población afectada.

Palabras clave: enfermedad falciforme; exclusión social; bioética de la intervención; COVID-19

\section{Intervention bioethics as a social inclusion possibility for sickle cell anemia patients in times of COVID-19}

\begin{abstract}
: this paper discusses from the perspective of intervention bioethics the social exclusion experienced by Brazilian individuals suffering from sickle cell anemia. It is an inherited disease where the gene responsible for the hemoglobin differential format is generationally passed on. It has more incidence in the afro-descendant population than any other, given that this hemoglobin format alteration was an evolutionary response to prevent malaria in the African continent. Besides the social exclusion that this population suffers, there is an even greater degree of discrimination resulting from the disease's effects. It has been recently discovered that COVID-19 has worsened the difficulties faced by patients with this disease. Therefore, drafting intervention-bioethics-based public policies whose main focus relies on vulnerability and the persistent challenges of society is proposed as a possible action to reduce the consequences of patients suffering from sickle-cell anemia.
\end{abstract}

Keywords: Sickle-cell anemia; Social exclusion; Intervention Bioethics; COVID-19. 


\section{Introdução}

O elevado número de nascimentos de crianças no Brasil identificadas pelo "teste do pezinho" como portadoras dos traços falciformes torna relevante o levantamento sobre o tema. Identifica-se que, embora o Ministério da Saúde tenha realizado levantamentos e protocolos de atuação dentro do Sistema Único de Saúde (sus), os avanços nos cuidados, principalmente da população adulta, não foram sentidos na prática.

O interesse pela análise da doença falciforme, sob o aspecto da bioética da intervenção, vem da possibilidade de trazer ao leitor um pensamento crítico sobre a preocupação das políticas em saúde para solucionar impasses existentes no tratamento de uma doença que está concentrada em uma população que geralmente não faz parte da elite social, econômica e política.

O preconceito e a discriminação em relação à população menos abastada são condições históricas ainda não superadas em todo o Brasil. Independentemente de ser parcela significativa da sociedade brasileira, ainda se encontra na base da pirâmide social, consoante dados estatísticos do Instituto de Pesquisa Econômica Aplicada (1). Ademais, considerando a distribuição étnica da doença falciforme na sociedade, sua incidência é majoritária na população negra, o que implica um agravamento da situação de preconceito e de exclusão social.

Dessa forma, neste artigo, discute-se sobre a maneira que a doença falciforme interfere na condição preexistente de exclusão social da referida população e a exacerba. A metodologia respalda-se em pesquisas de natureza exploratória, com levantamento bibliográfico e documental, voltadas para o estudo e a aplicação da bioética da intervenção quanto à doença falciforme.

Nesse sentido, em vista do atual contexto mundial de pandemia, demonstra-se que os acometidos pela doença falciforme se caracterizam como pertencentes dos chamados "grupos de risco", de modo que as dificuldades, já enfrentadas por eles, são exacerbadas.

\section{Doença falciforme}

Define-se como hemoglobinopatia o conjunto de distúrbios hereditários relacionados com os genes responsáveis pela síntese de proteínas globulares. Essas, denominadas de globinas, são capazes de transportar oxigênio e outros gases. As hemácias, células redondas presentes no sangue, são constituídas por um pigmento avermelhado denominado de hemoglobina A, que é responsável por efetuar a circulação de oxigênio para todo o corpo (2).

Estima-se que aproximadamente $7 \%$ da população mundial apresente algum tipo de doença ou afetação relacionado à hemoglobina $(\mathrm{Hb})$, sendo que a enfermidade hereditária mais prevalente é a doença falciforme (3). A expressão "doença falciforme" caracteriza-se pela presença da hemoglobina $S$ (Hbs) na corrente sanguínea, ou seja, abarca o conjunto das hemoglobinopatias que apresentam associações com a hemoglobina s. Entre as variações predominantes - $\mathrm{Hb}$ ss, a $\mathrm{Hb}$ s-beta Talassemia e as duplas heterozigoses $\mathrm{Hb} \mathrm{SC}$ e $\mathrm{Hb} \mathrm{SD}-$, a de maior recorrência é a anemia falciforme (4).

Os portadores da anemia falciforme não exercem de forma satisfatória a função de transporte de oxigênio, visto que o formato da hemoglobina $\mathrm{Hbs}$ consiste no equivalente ao de uma "meia lua" ou foice, o que acarreta na obstrução de artérias e veias. Essa situação faz com que o organismo não receba a quantidade necessária de oxigênio para o pleno desenvolvimento de suas funções, o que contribui para a elevada taxa de mortalidade dos portadores $(5,6)$. Constata-se que, em média, nascem 3.500 pessoas com a anemia falciforme por ano, das quais $20 \%$ não chegam a completar cinco anos de idade, conforme dados do Ministério da Saúde brasileiro (7).

Dessa forma, o afetado herda de seus progenitores o gene responsável pelo formato diferenciado da hemoglobina. Por sua vez, é importante diferenciar o desenvolvimento da anemia da condição de ser portador do gene, visto que existem inúmeras combinações genéticas possíveis entre esse gene e as hemoglobinas. O indivíduo que não manifesta a enfermidade é conhecido como possuidor 
de "traço falciforme" e, de acordo com a média brasileira, nascem por volta de 200.000 habitantes por ano com ele (4). Ademais, apresenta maior incidência na população negra, devido à alteração do formato da hemoglobina ter sido resultado da evolução do próprio corpo para evitar a contração da malária no continente africano. Ocorre que a população brasileira foi constituída em sua base pela imigração forçada dos povos vindos da África e, como a doença é hereditária, os portadores são predominantemente negros (5).

O tratamento dessa enfermidade consiste apenas em amenizar o sofrimento e as complicações ocasionadas aos portadores, visto ser uma doença incurável. Como consequência da baixa oxigenação, as hemácias agrupam-se no vaso sanguíneo e impossibilitam o devido fluxo de sangue; assim, ocasionam as manifestações mais frequentes, como: (i) fortes dores ósseas, que, além de permanecerem por dias, são a principal causa de morbidade entre os doentes; (ii) infecções e viroses; (iii) surgimento repentino de graves anemias ferroprivas; (iv) inchaço das mãos e dos pés (síndrome mão-pé); (v) acidentes vasculares cerebrais; (vi) icterícia; (vii) pneumonia; (viii) ulcerações e (ix) aplasia medular (6). Conviver com tais sintomas afeta diretamente a qualidade de vida desses indivíduos, motivo pelo qual a depressão, a ansiedade e o estresse são fatores recorrentes entre os pacientes (7).

Entre as opções de tratamento, está a utilização de medicamentos disponibilizados pelo Ministérios da Saúde (8): ácido fólico, analgésicos, antiinflamatórios, quelantes de ferro, imunobiológicos especiais e de antibioticoterapia. Outra tentaiva de ampliar o tempo de vida dos enfermos é a realização de exames preventivos, como, por exemplo, o doppler transcraniano, que identifica o risco de acidente vascular celebral em pessoas com doença falciforme que tenham entre 2 e 16 anos.

Consideram como tratamento curativo o transplante alogênico de células-tronco hematopoéticas (transpante de células-tronco), pois estudos trazem indicativos de aumento na sobrevida daqueles que o realizaram. Contudo, não existe um consenso sobre o encaminhamento de pacientes com anemia falciforme que devem ser submetidos ao transplante, pois deve ser satisfeita uma série de variáveis para a sua realização, que vão desde o contexto socioeconômico, a idade do paciente, a existência de doença que esteja associada até a possibilidade de encontrar um doador compatível (10). Dito isso, relevante salientar que a principal causa de morte por complicações precoces é a doença do enxerto contra o hospedeiro aguda, que pode ocorrer nos primeiros 100 dias após o transplante. Essa doença surge em decorrência da reação das células imunológicas que vêm do doador, particularmente linfócitos $\mathrm{T}$, contra os tecidos do receptor, tendo como principal alvo a pele, o trato gastrointestinal e o fígado (11).

O diagnóstico é realizado nos primeiros dias de vida da criança, pelo exame da triagem neonatal, conhecido popularmente como o "teste do pezinho". Para aqueles que não realizaram o teste ao nascer, existem duas opções complementares entre si: o teste do afoiçamento e a eletroforese de hemoglobina (8). O teste do afoiçamento realiza a identificação da hemoglobina s por meio da inserção de uma substância redutora de oxigênio no sangue, estimulando a formação de hemácias afoiçadas. Ressalva-se que esse exame não diferencia os indivíduos com a doença falciforme daqueles que têm, apenas, o traço falciforme (12). Portanto, tem-se a eletroforese de hemoglobina, em que o sangue é submetido a uma corrente elétrica que possibilita a diferenciação das hemácias por meio da taxa de migração das moléculas, vez que se dividem em função da diferença de peso, existente entre as hemácias saudáveis e as doentes (13).

Irala e Rodrigues (14) apresentam em seus estudos que os pacientes com essa doença podem apresentar complicações, tais como: aumento das câmeras cardíacas, hipertrofia do ventrículo, insuficiência cardíaca, derrame do pericárdio drenado, hipertensão arterial, pneumopatia, insuficiência da válvula mitral e tricúspide, cardiopatia crônica, cardiopatia estrutural, infarto esplênico e miocárdiopatia diastólica. Também constataram que há uma alta frequência de complicações pulmonares nesse grupo.

Vieira, Campos, Araujo, Lopes, Ibiapina, Fernandes (15) apontam que a síndrome toráxia aguda é causa de até $25 \%$ dos óbitos daqueles com 
esse doença, o que incide em uma vulnerabilidade ainda maior dessa população. Afinal, por suas características fisiológicas, são mais suscetíveis ao acometimento mais gravoso para os diversos tipos de enfermidades respiratórias, o que leva à necessária atenção redobrada para essas, como exemplo, a asma.

Para Ware, de Montalembert, Tshilolo, Abboud (16), a dor aguda é a principal característica clínica da anemia falciforme; costuma durar de 4 a 6 dias e ocorre nos braços, nas pernas, nas articulações, no tórax, no abdômen e nas costas. Além disso, como característica, pessoas com anemia falciforme são mais propensas a adquirir infecções, principalmente aquelas causadas por microorganismos encapsulados, como Streptococcus pneumoniae e Haemophilus influenzae tipo b, que podem ocasionar pneumonia, sepse e meningite.

Além das manifenstações agudas relatadas acima, ocorrem também complicações de ordem crônica, como retinopatias, necroses avasculares, declínio neurológico, úlceras nas pernas e priapismo recorrente. Essas estão diretamente associadas com a morbidade e com a diminuição da qualidade de vida. Outros desfechos recorrentes, que merecerem destaque, são a disfunção renal e as doenças cardiopulmonares, já que apresentam o maior índice de letalidade (16).

Todos os fatores supramencionados demonstram a relevância em se falar na doença falciforme, diante do prejuízo à saúde e à qualidade de vida dos indivíduos afetados. É clara a importância de acompanhamentos médicos e tratamentos adequados para eles, tendo em vista, principalmente, $o$ alto índice de mortalidade.

\section{Doença falciforme no contexto da saúde pública brasileira}

No atual momento do Estado Democrático de Direito, torna-se responsabilidade pública atribuir e concretizar os direitos sociais para a população, em sua totalidade. Ou seja, o Estado é responsável por prover os bens e os serviços mínimos para uma vida digna, como, exemplo, o direito à saúde. Nessa linha de raciocínio, para que haja a efetivação de uma cidadania plena, é de extrema importância que o direito à saúde, previsto no artigo $6^{\circ}$ da Constituição da Republica Federativa do Brasil, seja concretizado $(17,18)$.

Atualmente, a efetivação desse direito cabe ao sus, que, resumidamente, é o conjunto de serviços de saúde prestados pelos órgãos e pelas instituições públicas municipais, estaduais e federais, com o objetivo de universalizar a saúde (17). Além disso, possui como princípios fundamentais a equidade, a universalidade e a integralidade, pois visa ao acesso de todos os brasileiros de forma justa, impossibilitando qualquer espécie de discriminação (19).

Importante destacar que, para a efetividade do sus, é fundamental a existência de um conjunto de políticas sociais e econômicas que considerem a demanda e a necessidade da população, em conjunto com a capacidade de ofertar serviços de qualidade pelo Estado. Todavia, o modelo empregado para custear a assistência à saúde acarreta falhas ao ser colocado em prática, uma vez que existe um deficit na oferta dos serviços públicos em virtude da demanda populacional. Ocorre que o modelo criado para o atendimento desse sistema único não supunha uma diferença na prestação de serviços das subsedes regionais, o que altera o nível de qualidade e efetividade na prestação de serviços em saúde (20).

A estimativa do Ministério da Saúde é que o Brasil possua aproximadamente dois milhões de portadores do gene da $\mathrm{Hb} \mathrm{s}$ no Brasil e que 25 a 50 mil pessoas tenham a forma homozigótica (Hb ss) denominada de doença. $(21, \mathrm{~s} / \mathrm{p})$

No Brasil, a prevalência do traço falciforme é de $4 \%$, variando entre $2 \%$ e $8 \%$. Predomina nas regióes Norte e Nordeste, de maior contingente negroide, com frequência de $6 \%$ a $8 \%$; nas regiões Centro-Oeste e Sudeste, com frequência de $2,5 \%$, e na região Sul, com frequência em torno de $2 \%$. $(22, \mathrm{~s} / \mathrm{p})$

A portaria conjunta número 5 de 2018 (23) do Ministério da Saúde do Brasil, que aprova o Protocolo Clínico e Diretrizes Terapêuticas da Doença Falciforme, aponta o reconhecimento de que a doença falciforme é uma doença prevalente no Brasil, o que foi considerado determinante na instituição da Política Nacional de Atenção 
Integral às Pessoas com Doença Falciforme do Ministério da Saúde. Esse documento alerta para a probabilidade de que $4 \%$ da população brasileira apresente o traço falciforme (heterozigose simples) e que de 25.000 a 50.000 pessoas possuam a doença em estado homozigótico (ss - anemia falciforme) ou na condição de heterozigotos compostos ou duplos (SC, SE, SD, sBetaTAL - doença falciforme). No ano de sua publicação, foi apontado como estimativa de 60.000 a 100.000 casos (23).

Embora haja um número expressivo de pessoas acometidas com o gene, a doença não é considerada como passível de obter o benefício previdenciário do auxílio-doença. Esse benefício é realizado pelo governo, por meio do Instituto Nacional do Seguro Social (INSs) (24), com o intuito de conceder renda mensal mínima e indispensável para o beneficiário (25), conforme dispõe o artigo 47, II, anexo XLV, da Instrução Normativa 77/2015 do INss (26). Saliente-se que a simples presença da doença já é considerada como fator limitante para a contratação dos enfermos, o que oportuniza a maior taxa de desemprego e, assim, a prevalência deles em faixas socioeconômicas menos abastadas (27).

Nesse contexto, a ausência de suporte financeiro, aliado à insuficiência das políticas públicas, propicia a baixa qualidade de vida dos portadores da doença falciforme. Consequentemente, o Brasil atinge um elevado índice de mortalidade, motivo pelo qual se faz imprescindível a maior atenção tanto do sistema de promoção social quanto do sistema público de saúde (28).

Segundo a presidente da Associação de Pessoas com Doença Falciforme e Talassemia do Estado de Minas Gerais, Maria Zenó Soares, os acometidos pela doença falciforme

sofrem racismo por ser pobre, por ser negro e por ter a doença. A discriminação de profissionais da saúde de não acreditar no nosso relato no momento de dor é grande, principalmente nos serviços de urgência e emergência, considerando-nos como pessoas viciadas em morfina. A invisibilidade da doença falciforme se dá devido ao racismo das instituições de saúde. (29, s/p)

Esclarece-se que o racismo institucional se revela pela incompetência das instituições em dispor um serviço de qualidade para todos, sem distinções, por meio de seus profissionais. Não obstante, tais atitudes explicitam a desconsideração dos princípios fundamentais do sus.

Portanto, os indivíduos brasileiros com a doença falciforme também enfrentam situações características da pobreza, como exemplo, a dificuldade em arcar com os custos de locomoção dos pacientes até os hemocentros, dificultando o acompanhamento e o comparecimento a consultas (30). Ademais, enfatiza-se o fator da escolaridade, visto que o baixo nível de educação é incidente recorrente em $85 \%$ dos acometidos pela doença, os quais podem apresentar dificuldades para a compreensão das orientações e dos tratamentos.

Alude-se para o caso das mães de crianças com a doença falciforme, em que o cuidado com os filhos é intenso e constante (principalmente nos momentos de crises de dor), o que impede o exercício de atividades externas, notadamente o emprego formal. Logo, agrava-se tanto a situação de baixa renda dessas famílias quanto o estresse, a angústia e a sobrecarga diária $(31,32)$.

Tendo em vista o atual conceito de saúde da Organização Mundial da Saúde (oMs), como sendo "um estado de completo bem-estar físico, mental e social e não somente ausência de afecções e enfermidades" (33, s/p), percebe-se que a saúde perpassa a habitual compreensão de apenas portar determinada doença, ou seja, o termo "saúde" engloba toda a questão psicológica e social dos indivíduos.

Dessa maneira, é possível inferir que os acometidos pela doença falciforme não se enquadram como saudáveis, pois, mesmo enfermos, não lhes é concedido qualquer apoio ou política estatal que preze pelo seu bem-estar psicológico e social.

Assim, depreende-se que o conceito de cidadania está distante para esse grupo; nesse caso, pode ser definido como um "exercício de alguma forma hipócrita de apenas se tolerar a existência da diversidade" (34, p. 39).

\section{Exclusão social}

"Exclusão social" é uma expressão de difícil conceituação ou definição precisa. Contudo, todas as tentativas de conceito pela literatura científica aludem às minorias, às partes marginalizadas da 
sociedade que não conseguem exercer seus direitos mínimos, visto que essas camadas sociais não são consideradas como constituintes de indivíduos dignos de deveres e direitos. Ou seja, caracterizam-se por serem aqueles que "não têm direito a ter direito" $(18,35)$. Nesse sentido, nota-se uma controvérsia com o disposto no artigo $5^{\circ}$ da Constituição Federal (36), segundo o qual "todos são iguais perante a lei, sem distinção de qualquer natureza, garantindo-se aos brasileiros e aos estrangeiros residentes no País a inviolabilidade do direito à vida, à liberdade, à igualdade, à segurança e à propriedade".

Pode-se dizer também que a exclusão social e a cidadania deficitária são representações de uma sociedade não tolerante, individualista, que apresenta dificuldade para reconhecer, no outro, direitos que lhe são próprios, que discrimina com base em diferenças raciais, religiosas ou de gênero (35).

Para além da exclusão social, os níveis de desigualdade estão cada vez maiores na sociedade brasileira. Corroborando com essa informação, tem-se o relatório "País estagnado: um retrato das desigualdades brasileiras", proporcionado pela Oxfam em 2018. Conforme informações pertinentes a 2016 e a 2017, a diminuição da desigualdade de renda brasileira foi interrompida, o que fez o Brasil atingir a nona posição no ranking de país mais desigual do planeta.

Assim, os ganhos relativos aos mais pobres do país que significavam mensalmente o valor per capita de $\mathrm{R} \$ 217,63$ foram reduzidos para o importe de $\mathrm{R} \$ 198,03$, sem levar em consideração aspectos inflacionários (1).

Infere-se que os indivíduos que estão excluídos socialmente e se encaixam em uma faixa de desigualdade tão discrepante não conseguem exercer sua cidadania, se conceituada como sendo o direito de cada indivíduo de usufruir dos benefícios essenciais e de participar da sociedade.

Por sua vez, a não efetivação da cidadania alude à presença daqueles indivíduos que vivem e contribuem para a sociedade, mas que não possuem acesso a bens, consumos e serviços, independentemente da suposta garantia legal. Desse modo, para que a cidadania seja efetiva, os indivíduos devem emancipar-se e exigir mudanças sociais, para, assim, conseguirem a inclusão integral na sociedade $(37,18)$.

Nessa linha, Gustin afirma que:

Conceitua-se cidadania como a democratização de relações para sustentação da diversidade. Essa diversidade pode ser étnica, religiosa, de gênero, socioeconômica, dentre outros elementos. Os pressupostos de democratização na formação dos seres podem se dar por meio do desvendamento e da desocultação das variadas formas de violências contra o ser humano, do resgate do "princípio de comunidade", das relações horizontalizadas e coextensivas e do estímulo ao desenvolvimento de competências individuais, interpessoais e colaborativas. (37, p. 15)

Assim, o acesso igualitário ao tratamento deve ser visto como algo a ser buscado de maneira precípua, pois, ao dar a oportunidade de saúde de forma equitativa, haverá a possibilidade de dizer que a população brasileira é tratada dentro dos preceitos bioéticos, levando em consideração uma perspectiva mais ampla do que são os princípios da beneficência, da justiça, da autonomia e da não maleficência. Ainal, os aspectos a serem considerados nesse contexto ultrapassam a visão clínica do paciente.

\section{Doença falciforme e COVID-19}

Segundo a oms (2020), a COVID-19, doença provocada pelo novo coronavírus, desenvolve-se como uma virose leve em $80 \%$ dos casos, que apresenta como sintomas febre, mialgia, tosse seca, dor de garganta, congestão nasal e cefaleia. Contudo, importa dizer que, em $20 \%$ dos casos, os pacientes desenvolvem manifestações de disfunção pulmonar na forma de pneumonia intersticial grave, síndrome respiratória aguda, sepse e choque séptico.

A Associação Brasileira de Hematologia, Hemoterapia e Terapia Celular (38) afirma que cerca de 70.000 brasileiros que são acometidos pela doença falciforme correm sério risco nesse contexto, pois a baixa imunidade desse grupo o coloca em risco de desenvolver a forma mais grave da COVID-19. Alerta ainda para um dado relevante:

Uma das principais causas de morbimortalidade nesses indivíduos é a síndrome torácica aguda (sTA), que 
é o termo usado para uma constelação de achados que incluem dor no peito, tosse, febre, hipóxia (baixo nível de oxigênio) e infiltrados pulmonares. A síndrome torácica aguda pode ser resultado de falcização nos pequenos vasos sanguíneos, infarto/embolia pulmonar ou pneumonia viral ou bacteriana. $(38$, p. 1$)$

Nesse mesmo sentido, Vieira, Campos, Araujo, Lopes, Ibiapina, Fernandes (15) destacaram, em seu artigo, que o pulmão é um dos órgãos mais acometidos pela doença falciforme e, por ser uma doença genética, é causa de morbidade desde a infância. Colocando também esse grupo, o das crianças, dentro da necessidade de alerta para a infecção por coronavírus.

Irala e Rodriques (14) também corroboram para que a preocupação no momento da pandemia da COVID-19 seja elevada para os acometidos pela doença falciforme, pois, ao analisarem o recorte das doenças pulmonares, chegaram à seguinte conclusão:

O estudo revela alta frequência de 65\% de complicações pulmonares na anemia falciforme, indicando ser um problema de saúde pública que interfere na qualidade de vida dos pacientes. Revela também a variação entre o sexo feminino e masculino; no sexo masculino as complicações pulmonares são de $62 \%$ e $38 \%$ não possuem complicações pulmonares e no sexo feminino 41\% dos casos possuem algum tipo de complicação pulmonar e 59\% não possuem complicações, perante as complicações pulmonares (STA, hipertensão pulmonar e infecções) e o tratamento por hidroxiúreia, com a frequência de $52 \%$ dos pacientes fazem tratamento e $48 \%$ não fazem. Por esses motivos é importante que os profissionais de saúde se atentem para estas complicações quando estiverem tratando estes pacientes. Além disso, as complicações devem ser consideradas no planejamento das políticas de saúde voltadas para anemia falciforme. (14, p. 36)

De forma a concluir que a população com doença falciforme se encontra no chamado "grupo de risco", o que é potencializado por, em sua grande maioria, acometer a população carente. Macedo, Ornellas e Bomfim (39) enfatizam que, para que ocorra a necessária prevenção ao contágio e a redução das taxas crescentes da pandemia, faz-se necessária a aplicação das medidas de isolamento e higiene; contudo, para isso, seria primordial a existência de políticas de saneamento básico e abastecimento. Ainda, destacam:

É necessário mais que declarar Estado mínimo, é necessário repensar as ações de Esgotamentos Sanitários nessas áreas subalternizadas; Abastecimento de água como condição mínima a todos os cidadãos; Acesso à educação gratuita, pública e de qualidade; políticas de promoção de saúde públicas. Pois, é nas instituições públicas e nas universidades que se produz mais de $90 \%$ da ciência no Brasil. (39, p. 9)

Jesus, Konstantyner, Lôbo, Braga (30) observam, em seu estudo, que os doentes falciformes são, em sua grande maioria, menos abastados e que os problemas socioculturais se perpetuam nessa população, o que resulta na necessidade de um pensamento integral para que as políticas públicas se adaptem de forma a atingir as camadas sociais que mais necessitam neste momento.

Assim, para além das características da doença, que se destaca na população de pele negra, pobre e que normalmente vive em favelas, há que se preocupar com a falta de política específica para esse grupo em um momento tão delicado.

Conforme demonstram os estudos, por suas características, essa população encontra-se no grupo caracterizado como "de risco" para a COVID-19, que é composto pelos idosos e pelas pessoas que apresentam outras condições de saúde subjacentes, como hipertensão arterial sistêmica, cardiopatias, diabetes mellitus, doenças respiratórias crônicas, doenças imunodepressoras, entre outras (40). Dessa forma, a invisibilidade, que já era latente, pode se transformar em desastrosa diante das escolhas políticas realizadas, ao longo de décadas, por nossos governantes.

Importa dizer que o atual momento em que a pandemia da COVID-19 assola os cidadãos, tornase necessária a unidade governamental focada em um objetivo único: o de salvar vidas. Porém, a sociedade presencia a exacerbação das diferenças políticas, as declarações divergentes em relação aos métodos de controle do contágio e, assim, a certeza de que os interesses próprios dos políticos sobrepõem à vida dos mais humildes. 


\section{Um olhar da bioética da intervenção para a doença falciforme}

A bioética de intervenção é uma ética aplicada que almeja reduzir as desigualdades sociais por meio de medidas interventivas rígidas no campo social. Ela protege os direitos fundamentais, previne ou interrompe os abusos realizados contra as pessoas vulneráveis (aquelas injustiçadas pela relação assimétrica de poder) e visa à conquista dos direitos primários para todos os indivíduos. Além disso, prioriza decisões que beneficiem o maior número de pessoas e que demonstrem melhores consequências coletivas (41-43).

Ainda, está sempre em transformação devido à necessidade da renovação ética e dos ordenamentos jurídicos, almejando a conquista da igualdade social por meio da conjugação de compromisso e responsabilidade da população como um todo (42, 44). Para tanto, fundamenta-se em ações multidisciplinares, que incluam além das ciências médicas e biológicas, o Direito, a Sociologia, a Filosofia, a Antropologia, a Economia e as Ciências Políticas (45).

$\mathrm{Na}$ história do desenvolvimento da bioética de intervenção, destacam-se três momentos. No primeiro, verificou-se o sofrimento da população devido à desigualdade de poder e à limitação de direitos mínimos. Posteriormente, o objetivo da bioética de intervenção voltou-se para a compreensão e a defesa dos Direitos Humanos universais, diante da situação de inacessibilidade aos bens de consumo básicos e da sobrevivência com dignidade. Por fim, o terceiro momento relacionou-se às autocríticas ao próprio fundamento bioético utilitário, uma vez que ele depende da capacidade racional de determinar o que realmente seria um privilégio ou apenas o melhor para a sociedade em geral, para o maior número possível de pessoas (42).

Dessa forma, é perceptível que a bioética da intervenção reclama por direitos com o condão de tornar a sociedade mais igualitária, resultante de uma política de transformação social que promova uma possível igualdade para toda a população, a partir de ações que deem a devida importância e possibilitem o bem-estar da coletividade humana.
Porém, para que isso seja possível, é necessário que os indivíduos desfavorecidos e vulneráveis se tornem sujeitos empoderados e emancipados (42).

$\mathrm{O}$ ato de empoderar define-se pelo reconhecimento, realizado pelo próprio indivíduo, de sua totalidade física e psíquica, de forma que lhe permita manifestar-se perante a sociedade desigual em que se encontra, em busca de sua valorização como sujeito igual em direitos e deveres. Já a emancipação é a maneira segundo a qual o sujeito se torna livre, responsável pelos seus atos e decisões, sem depender do outro, é a possibilidade de o próprio sujeito realizar suas escolhas independentemente da opinião alheia. Unindo esses dois atributos, os sujeitos terão possibilidade de realizar uma crítica à realidade social (43).

Outra vertente dentro da linha intervencionista da bioética permite a discussão da contradição ética entre o progresso científico e as medidas sanitárias básicas. Enquanto alguns hospitais do país tratam morbidades atuais e complexas, como exemplo, as intervenções cardíacas intrauterinas em fetos, existem, em contraposição, uma grande quantidade de indivíduos que morre diariamente por doenças decorrentes da não efetivação do saneamento básico. Portanto, é possível observar que o Brasil é um país em que a riqueza e o acesso à saúde são possíveis para apenas uma parte da população, o que provoca miséria e sofrimento em uma grande parcela populacional (45).

A bioética da intervenção cuida também de fazer uma reflexão relativa aos comportamentos humanos, no que tange à individualidade e à autonomia, a fim de não atingir os direitos do outro, enfatizando que a tolerância, a responsabilidade, a solidariedade e a libertação são referenciais bioéticos que devem ser aplicados a qualquer ato humano $(44,45)$. Ademais, estabelece que as políticas de saúde e as ações governamentais devem fundamentar-se na equidade, na solidariedade e em investimentos que privilegiem as classes socialmente menos favorecidas (46).

Salienta-se, nesse contexto, que algumas doenças e incapacidades prejudicam o modo de vida e as oportunidades dos indivíduos, limitando a atuação deles para se tornarem cidadãos participativos na vida social, política e inclusive econômica 
da sociedade. Desse modo, as políticas públicas são insatisfatórias para a situação atual da sociedade, sendo necessário que o Estado realize ações efetivas para possibilitar a diminuição das desigualdades e o aumento do bem-estar da população como um todo (41).

Em face do exposto, é imperioso que o indivíduo seja considerado em sua totalidade, e não mais reduzido à sua incapacidade ou enfermidade, o que é vedado pelo Estatuto da Pessoa com Deficiência. Em seu artigo 1º, a Lei 13.146 de 2015 deixa clara a intenção do legislador, ao afirmar que ela é "destinada a assegurar e a promover, em condições de igualdade, o exercício dos direitos e das liberdades fundamentais por pessoa com deficiência, visando à sua inclusão social e cidadania". No caso dos portadores da doença falciforme, é necessário que passem a ser tratados como parcela vulnerável da população brasileira e que, portanto, sejam destinatários de políticas públicas específicas que garantam o tratamento isonômico e a inclusão social igualitária, tornando-os participativos socialmente.

\section{Conclusão}

A partir dos argumentos expostos, pretendeu-se provocar uma reflexão diante das dificuldades enfrentadas pelos indivíduos com a doença falciforme em um contexto de exclusão social e de insuficiência do alcance do atendimento à saúde pública.

Entende-se que o Brasil, por ser um país multicultural, deveria possuir políticas públicas focadas nas diferenças culturais e étnicas, especialmente em face do atual contexto de um Estado Democrático de Direito. Todavia, não é a realidade enfrentada por diversos grupos sociais, entre esses, os portadores de doença falciforme, em que, além das intensas dores e das complicações advindas da doença durante toda a vida, os tratamentos propiciados são imprecisos e incompletos. Percebe-se que os portadores da doença falciforme, além de serem injustiçados socialmente, vivem, em regra, em situação considerada precária, com renda insuficiente para arcar com as despesas provenientes da enfermidade.
Tal conjuntura foi exacerbada pelas medidas adotadas pelo governo, em alguns momentos, seguindo orientações internacionais para o controle da pandemia da COVID-19. A situação de descaso pode ser verificada nos pedidos de isolamento social e de higiene, vez que esses não foram acompanhados de atitudes eficazes, tanto para a manutenção de renda mínima quanto para o acesso aos materiais considerados indispensáveis para a limpeza das mãos e dos utensílios.

Destaca-se também que a população, em meio à disseminação de um vírus letal, precisou enfrentar a crise política provocada pelo então presidente e sua equipe ministerial. Um claro embate que, de um lado, tem-se as vontades individuais de quem está no poder, enquanto, do outro, a dificuldade de sobrevivência e subsistência do povo brasileiro. Já no que concerne à economia, faz-se presente, novamente, a crença de que o desenvolvimento do país deve ser sustentado pelos menos abastados para a manutenção dos lucros e da qualidade de vida dos mais ricos.

Ademais, a relação entre a saúde pública e a doença falciforme é insatisfatória, uma vez que o Estado não promove assistência necessária para essa enfermidade, como se pode observar com a não realização de benefícios relativos aos doentes, visto a sua não inclusão no programa auxílio-doença. Dessa maneira, o direito à saúde garantido pela Constituição Federal não é efetivado para os cidadãos com doença falciforme, opondo-se aos ideais democráticos.

Portanto, não sendo incluídos em nenhuma das possibilidades de renda previdenciária, os acometidos por essa doença foram obrigados a verificar as exigências de inclusão em um auxílio emergencial. Esse foi criado com o intuito de permitir a manutenção do isolamento social, possibilitando, ainda, o destaque para mais um ponto de ineficiência das ações governamentais. Afinal, as exigências para o pagamento, os erros em aplicativos, a falta de critérios bem-definidos e de uma comunicação realmente eficaz com a população provocaram filas quilométricas por todo o país.

Mais uma vez, as ações de voluntários buscaram atender uma demanda da sociedade em que os governantes brasileiros insistem em renegar. 
Campanhas de doações diversas foram criadas para minimizar a secular falta de ação para com as camadas menos abastadas.

A transformação dos contaminados e dos falecidos pela COVID-19 em números leva a uma relativização do real problema enfrentado. A falta de ventiladores pulmonares, de leitos de unidade de terapia intensiva e de equipamentos de proteção individual para os profissionais atuantes na "linha de frente" do combate ao vírus reflete em árduas escolhas realizadas pelas equipes de saúde, as quais retiram e isolam avós, pais, irmãos e filhos, com nome e sobrenome, do convívio de suas famílias. Muito mais do que discutir princípios, é primordial cobrar ações.

As mudanças sociais da sociedade brasileira demonstram a necessidade da intervenção efetiva do Estado. Nesse contexto, a bioética da intervenção surge como fator orientador para a atual crise do sistema de saúde, decorrente da ausência de políticas públicas adequadas e da ineficiência daquelas que estão em vigor, proporcionando maneiras eficazes para o amparo dos indivíduos vulneráveis.

É mais do que necessário pensar em uma sociedade que tenha uma melhor distribuição de recursos, especialmente em um momento que pesquisadores se perguntam a melhor forma de lidar com um vírus que, por mais que seja capaz de afetar a todos, afete a sociedade como um todo, possui drásticas consequências para aqueles que se encontram em classes desfavorecidas economicamente.. Haja vista que, nos casos de infecção, especialmente nas camadas menos abastadas da sociedade, a sobrevivência certamente será menor.

Podemos mencionar que, no Brasil, o primeiro caso relatado de infecção, pelo vírus causador da COVID-19, foi de uma empregada doméstica que possivelmente foi infectada pelo empregador, voltando de uma viagem de férias. Por isso, devemos reiterar e reforçar que a população que mais sofrerá com os efeitos da atual pandemia é a mesma população que já sofre de diversas doenças, incluindo anemia falciforme, que, por suas características, já colocam os pobres em consonância com as mortes que estão por vir.

Contudo, isso somente ocorrerá quando os governantes trabalharem para a construção de uma sociedade justa e solidária, aspirando a erradicação da pobreza, realocando recursos para a saúde e reduzindo as desigualdades sociais e regionais. Apenas assim o Estado poderá arcar com sua obrigação de assegurar a igualdade, a liberdade, a dignidade, $\mathrm{o}$ acesso à educação e à saúde.

No âmbito dos acometidos pela doença falciforme, a bioética da intervenção propõe a responsabilidade dos governantes, em conjunto com a sociedade em geral, de modo que não mais seja admitida a persistente supressão dos seus direitos, para que assim seja possível, além de ampliar a disponibilização de recursos, orientações e adequação do tratamento ofertado pelo sus, garantir a devida qualidade de vida a esses indivíduos, que, em nenhum momento, deixaram de ser integrantes da população brasileira.

\section{Referências bibliográficas}

1. Instituto de Pesquisa Econômica Aplicada (Ipea). Situação social da população negra por estado. Disponível em: http://www.ipea.gov.br/portal/images/ stories/PDFs/livros/livros/livro_situacao-social-populacao-negra.pdf

2. Figueiredo SV, Lima LA, Silva DPB, Oliveira RMC, Santos MP, Gomes ILV. Importância das orientações em saúde para familiares de crianças com doença falciforme. Rev Bras Enferm. 2018;71(6):3150-8.

3. Gomes LMX, Pereira IA, Torres HC, Caldeira AP, Viana MB. Access and care of individuals with sickle cell anemia in a primary care service. Acta Paul Enferm. 2014;27(4). DOI: http://dx.doi.org/10.1590/19820194201400058

4. Centro de Educação e Apoio para Hemoglobinopatias (CEHMOB). Doença falciforme. Disponível em: https://www.nupad.medicina.ufmg.br/pesquisa-e-projetos/acervo-cehmob/

5. Araújo FC, Sousa ÉQ, Rodrigues TN, Rodrigues IR, Melo DS, Monte APCS et al. Early diagnosis of sickle cell anemia: a literature review. 2020;9(4):e79942516-e79942516. DOI: http://dx.doi. org/10.33448/rsd-v9i4.2516

6. Núcleo de Ação e Pesquisa em Apoio Diagnóstico da Faculdade de Medicina: da UFMG. Racismo traz obstáculos à pessoa com doença falciforme. Disponível em: https://site.medicina.ufmg.br/inicial/racismo-institucional-traz-obstaculos-ao-paciente-com-doenca-falciforme/ 
7. Garioli DS, Paula KMP, Enumo SRF. Avaliação do coping da dor em crianças com Anemia Falciforme. Estud. psicol. Campinas [online]. 2019;36:e160079. Dor: http://dx.doi.org/10.1590/1982-0275201936e160079

8. Ministério da Saúde do Brasil. Secretaria de Atenção à Saúde. Doenças falciformes (DF) e outras hemoglobinopatias. Disponível em: http://www.saude.gov.br/acoes-e-programas/programa-nacional-da-triagem-neonatal/ doencas-falciformes-df-e-outras-hemoglobinopatias

9. Angelucci E et al. Hematopoietic stem cell transplantation in thalassemia major and sickle cell disease: Indications and management recommendations from an international expert panel. Haematologica. 2014;99:811-20.

10. Gluckman E. Allogeneic transplantation strategies including haploidentical transplantation in sickle cell disease. Hematology. 2013;2013(1):370-6. DoI: https://doi.org/10.1182/asheducation-2013.1.370

11. Hoffbrand AV, Moss PAH. Fundamentos em Hematologia. 6. ed. Porto Alegre: Artmed; 2013.

12. Centro de Ensino e Aperfeiçoamento Profissional (Cenapro). Exames para anemia falciforme. Disponível em: http://www.cenapro.com.br/noticias-detalhes.as$\mathrm{p}$ ? codigo $=1355$

13. Kasvi. A eletroforese de hemoglobinas no diagnóstico de anemia falciforme. Disponível em: https://kasvi. com.br/eletroforese-hemoglobina/

14. Irala LCP, Rodrigues R. Avaliação das complicações pulmonares na anemia falciforme em pacientes do hemocentro - Unicamp. Revista Foco: Caderno de Estudos e Pesquisas. 2017;24-37. Disponível em: https://revistafoco.inf.br/index.php/FocoFimi/article/ view/495

15. Vieira AK, Campos MK, Araujo IAD, Lopes GCS, Ibiapina CDC, Fernandes SDSC. Anemia falciforme e suas manifestações respiratórias. Rev Med Minas Gerais. 2010;20(4 supl 3):S5-1. Disponível em: http://rmmg.org/artigo/detalhes/924

16. Ware RE, de Montalembert M, Tshilolo L, Abboud MR. Sickle cell disease. The Lancet. 2017;390:311-23. doi: http://doi.org/10.1016/S0140-6736(17)30193-9

17. Ministério da Saúde do Brasil. sus - Princípios e conquistas. Disponível em: http://bvsms.saude.gov.br/bvs/ publicacoes/sus_principios.pdf

18 Schwartzman S, Reis E. Pobreza e exclusão social: aspectos sócio-políticos. Disponível em: http://www. schwartzman.org.br/simon/pdf/exclusion.pdf

19. Oliveira A, Biato S. Racismo Institucional Saúde. Revista de Serviço Social. 2019;1(3):118-38. Disponível em: http://publicacoes.unigranrio.edu.br/index.php/ mrss/article/view/5485/2935

20. Filho F, Sarti F. Falhas de mercado e redes em políticas públicas: desafios e possibilidades ao Sistema Único de Saúde. Ciên. Saúde coletiva. 2012;17(11). DoI: https://doi.org/10.1590/S1413-81232012001100015

21. Ministério da Saúde do Brasil. Manual da anemia falciforme para a população. Disponível em: http://www.cehmob.org.br/wp-content/ uploads/2016/06/Manual-da-Anemia-Falciforme-para-a-populacao.pdf

22. Cançado RD. Santa Casa de São Paulo. Anemia falciforme: um problema de saúde pública. Disponível em: https://santacasasp.org.br/portal/site/pub/12482/anemia-falciforme--um-problema-de-saude-publica

23. Ministério da Saúde do Brasil. Portaria Conjunta n. ${ }^{\circ}$ 5. Disponível em: http://portalarquivos2.saude.gov.br/ images/pdf/2018/fevereiro/22/Portaria-Conjunta-PCDT-Doenca-Falciforme.fev.2018.pdf

24. Instituto Nacional do Seguro Social (Inss). Auxílio-doença. Disponível em: https://portal.inss.gov.br/ informacoes/auxilio-doenca/

25. Júnior W. Lista de doenças graves que possibilitam ao segurado obter o benefício por incapacidade sem cumprir o período mínimo de carência. Jusbrasil. Disponível em: https://saberalei.jusbrasil.com.br/artigos/159432824/lista-de-doencas-graves-que-possibilitam-ao-segurado-obter-o-beneficio-por-incapacidade-sem-cumprir-o-periodo-minimo-de-carencia

26. Brasil. Instrução normativa InSs/PRES n. 77 , de 21 de janeiro de 2015. Reconhecimento de direitos dos segurados e beneficiários da Previdência Social. Diário Oficial da União. Disponível em: http://www.in.gov. br/materia/-/asset_publisher/Kujrw0TZC2Mb/content/id/32120879/do1-2015-01-22-instrucao-normativa-n-77-de-21-de-janeiro-de-2015-32120750

27. Lubeck $\mathrm{D}$ et al. Estimated life expectancy and income of patients with sickle cell disease compared with those without sickle cell disease. jama Netw Open. 2019;2(11):e1915374. DoI: https://doi.org/10.1001/jamanetworkopen.2019.15374

28. Felix A, Souza H, Ribeiro S. Aspectos epidemiológicos e sociais da doença falciforme. Rev. Bras. Hematol. Hemoter. 2010;32(3):203-8. DoI: https://doi.org/10.1590/ S1516-84842010005000072

29. Brito M. Núcleo de Ação e Pesquisa em Apoio Diagnóstico da Faculdade de Medicina: da UfMG. A dor silenciada da doença falciforme. Disponível em: https://www.nupad.medicina.ufmg.br/a-dor-silenciada-da-doenca-falciforme/ 
30. Jesus ACS, Konstantyner T, Lôbo IKV, Braga JAP. Características socioeconômicas e nutricionais decrianças e adolescentes com anemia falciforme: uma revisão sistemática. Rev. paul. pediatr.2018;36(4):491-9. DoI: https://doi.org/10.1590/1984-0462/;2018;36;4;00010

31. Yarboi J, Prussien KV, Bemis H, Williams E, Watson $\mathrm{KH}, \mathrm{McNally} \mathrm{C}$ et al. Responsive Parenting Behaviors and Cognitive Function in Children With Sickle Cell Disease. Journal of pediatric psychology. 2019;44(10):1234-43. DoI: https://doi.org/10.1093/ jpepsy/jsz065

32. Guimarães T, Miranda W, Tavares M. O cotidiano das famílias de crianças e adolescentes portadores de anemia falciforme. Rev. Bras. Hematol. Hemoter. 2009;31(1):9-14. DoI: https://doi.org/10.1590/S151684842009005000002

33. Marques AJS, Assis G, Dresc RL, Iunes R. Direito a saúde, cobertura universal e integralidade possível. Disponível em: https://www.almg.gov.br/export/ sites/default/acompanhe/eventos/hotsites/2016/encontro_internacional_saude/documentos/textos_referencia/001_theme_contextualization.pdf

34. Gustin M. Necessidades humanas, autonomia e o direito à inclusão em uma sociedade que se realiza na interculturalidade e no reconhecimento de uma justiça do bem-estar. Em: Pellegrini A, Almeida G, Gustin M, Lima P, Iennaco R, organizadores. Direitos fundamentais das pessoas em situação de rua. Belo Horizonte: Editora D’Plácido; 2016. pp. 31-49.

35. Nascimento E. Hipóteses sobre a nova exclusão social: dos excluídos necessários aos excluídos desnecessários. Cad. CRH. 1994;21:29-47. DOI: http://dx.doi. org/10.9771/ccrh.v7i21.18772

36 Brasil. Constituição da República Federativa do Brasil; 1988. Disponível em: http://www.planalto.gov.br/ccivil_03/constituicao/constituicao.htm

37. Gustin M, Caldas S. A prática de Direitos Humanos nos cursos de Direito. Disponível em: http://www. dhnet.org.br/educar/academia/textos/gustin_pratica_dh_curso_direito.pdf

38. Associação Brasileira de Hematologia, Hemoterapia e Terapia Celular (АВНH). Disponível em: https://abhh.org.br/wp-content/uploads/2020/03/ GLOBULOS-VERMELHOS.pdf

39. Macedo YM, Ornellas JL, Bomfim HF. COVID-19 no Brasil: o que se espera para população subalternizada? Rev Encantar - Educação, cultura e sociedade. 2020;2:1-10. Disponível em: https://revistas.uneb.br/ index.php/encantar/article/view/8189
40. Zhou M, Zhang X, Qu J. Coronavirus disease 2019 (COVID-19): A clinical uptade. Frontiers of Medicine. 2020;14:126-35. DOI: https://doi.org/10.1007/s11684020-0767-8

41. Morais T, Monteiro P. Conceitos de vulnerabilidade humana e integridade individual para a Bioética. Rev. bioét (Impr). 2017;25(2):311-9.

42. Garrafa V, Martorell L. Bioética de intervenção - uma breve síntese de seus fundamentos e aplicações em tempos de globalização e desigualdades sociais. Em: Siqueira J, Zoboli E, Sanches M, Pessini L, organizadores. Bioética Clínica. Brasília: CFM/sBB; 2016. pp. 73-91.

43. Silva L, Drummond A, Garrafa V. Bioética de intervenção: uma prática politizada na responsabilidade social. Universitas: Ciência e Saúde. 2011;9(2):111-9. DoI: https://doi.org/10.5102/ucs.v9i2.1510

44. Garrafa V. Apresentando a bioética. Rev. Universitas Humanas. 2006;3(1):1-12. Disponível em: https://www.publicacoesacademicas.uniceub.br/face/ article/view/118/102

45. Garrafa V. Reflexões Bioéticas sobre ciência, saúde e cidadania. Rev. Bioét. (Online). 1999; 7(1). Disponível em: https://revistabioetica.cfm.org.br/index.php/revista_bioetica/article/view/287/426

46. Barchifontaine C, Trindade M. Bioética, saúde e realidade brasileira. Rev. Bioét. (Impr.). 2019;27(3):439-45. DOI: 10.1590/1983-80422019273327 